\title{
Effect of Asymmetric Hydrodynamic Impact on the Dynamic Response
}

Jianbo Hua

Associate Professor, Department of Vehicle Engineering Royal Institute of Technology, Sweden

Jeun-Len Wu

Professor, Department of System Engineering and Naval Architecture, National Taiwan Ocean University, Keelung, Taiwan, R.O.C.

Wei-Hui Wang

Professor, Department of System Engineering and Naval Architecture, National Taiwan Ocean University, Keelung, Taiwan, R.O.C.

Follow this and additional works at: https://jmstt.ntou.edu.tw/journal

Part of the Engineering Commons

\section{Recommended Citation}

Hua, Jianbo; Wu, Jeun-Len; and Wang, Wei-Hui (2000) "Effect of Asymmetric Hydrodynamic Impact on the Dynamic Response," Journal of Marine Science and Technology. Vol. 8: Iss. 2, Article 2.

DOI: $10.51400 / 2709-6998.2456$

Available at: https://jmstt.ntou.edu.tw/journal/vol8/iss2/2

This Research Article is brought to you for free and open access by Journal of Marine Science and Technology. It has been accepted for inclusion in Journal of Marine Science and Technology by an authorized editor of Journal of Marine Science and Technology. 


\section{Effect of Asymmetric Hydrodynamic Impact on the Dynamic Response}

\section{Acknowledgements}

We highly appreciated the National Science Council of Republic of China for granting the financial support to the work under the Contract No.NSC-89-2811-E-019-0001. 


\title{
EFFECT OF ASYMMETRIC HYDRODYNAMIC IMPACT ON THE DYNAMIC RESPONSE OF A PLATE STRUCTURE
}

\author{
Jianbo Hua*, Jeun-Len $\mathrm{Wu}^{* *}$ and Wei-Hui Wang**
}

Keywords: asymmetric water entry, ship bottom structure, hydrodynamic impact, structural dynamic responses.

\begin{abstract}
Due to the asymmetric water entry over a submerged part of a ship, the effect of the hydrodynamic impact on the dynamic response of a plate structure is investigated numerically by employing an orthogonal plate theory. The effect is found significant in the calculation. Both the deflection and the stress in the plate increase as the asymmetric degree under water entry of a bottom structure increases. Because of the structural dynamic effect, the maximum deflection at a heel angle of 20 degrees becomes about $50 \%$ more than that of the quasi-static approach, and the maximum stress in $y$ direction $40 \%$ more than that of the quasi-state approach. The result of the present work proves the importance of asymmetrical hydrodynamic impact loading for structural design of a ship.
\end{abstract}

\section{INTRODUCTION}

In the past ten years the number of high-speed ships in commercial service has rapidly increased; meanwhile ship size has become larger with time. The newly designed ships about $150 \mathrm{~m}$ in length have been put into service and their speeds can be up to 40 knots. For such ships, structural designs can strongly influence ship weight, and simultaneously building cost and cargo capacity.

Local structural design is an integral part of ship structural design. Meanwhile the slamming impact load is one important phenomenon that must be taken into consideration in the local structural design. Furthermore the slamming impact becomes more severe as ship speed increases.

Asymmetric hydrodynamic impact on a ship occurs because of bow waves. Due to the wave excitation and the wind pressure on the superstructure, roll motion

Paper Received Oct. 1, 2000. Author for Correspondence: J. L. Wu. *Associate Professor, Department of Vehicle Engineering Royal Institute of Technology, Sweden

**Professor, Department of System Engineering and Naval Architecture, National Taiwan Ocean University, Keelung, Taiwan, R.O.C. of a ship in her seaway causes the ship fore body to be always asymmetrical in some degrees under water entry after it has been raised over the wave surface. Moreover the slope of wave elevation gives additional degrees of asymmetry. However the significance of this phenomenon is not yet commonly recognized, since the heading wave and the symmetric impact pressure are still used as design conditions. Nevertheless, in comparison with the symmetric hydrodynamic impact case, the effect of asymmetric impact on the structural dynamic response is expected to be more serious because the hydrodynamic pressure level becomes higher, especially at a short duration.

Hua [1] pointed out the importance of the problem when identifying the difficulties in the assessment of design loads for high speed vessels by theoretical approaches. Rosen and Rutgersson [2] conducting full-scale measurement of hydrodynamic pressure on a planing boat in waves also indicated that the bow wave gives higher pressure-level than the heading waves because of the asymmetric condition. Due to the short duration and the high pressure-level of the slamming impact, the response of the local structure can not be considered to be of quasi-static nature. The study by Milchert et. al. [3] on the dynamic response of a FRPpanel showed that the stress level can be up to $25 \%$ higher than average due to the structural dynamic effect. In fact, the structural dynamics can also give the opposite effect. Faltinsen in his study [4] concluded that the maximum stresses lower than those predicted by a quasi-steady theory are obtained when the effect of hydro-elasticity is large for a stiffed plate structure.

In this work the effects of asymmetric impact on the structural dynamic responses will be studied thoroughly. The orthogonal plate theory is employed to model the bottom plate structure. A method derived by Toyama [5] will be applied for the calculation of the transient pressure distribution on an asymmetric edged body under water entry. Thereby, the structural response will be simulated in time-domain using the Vlasov/Galerkin method to solve the governing differential equation of the dynamic behavior of an orthogo- 
nal plate.

\section{DESCRIPTIONS OF METHODS}

\section{Asymmetric slamming pressure distribution}

For the water entry of a symmetric edge body with a small dead-rise angle thown in Fig. 1, the Wagner's theory gives good result in predicting the slamming pressure distribution. With a constant drop velocity $V$, the slamming pressure distribution at a location $x$ takes the form

$$
\frac{p(\xi)}{\rho}=\frac{\pi}{2 \tan \beta} \frac{V^{2}}{\sqrt{1-\xi^{2}}}-\frac{V^{2}}{2} \frac{\xi^{2}}{1-\xi^{2}}, \text { where } \xi=\frac{x}{c}
$$

where $\beta$ is the dead-rise angle and $c$ is the half wetted length.

To calculate the asymmetric slamming pressure distribution, we adopt a simple method, which is an extension of the Wagner's theory and was derived by Toyama [5]. The pressure distribution along the wetted line is then determined by the following expression as

$$
\begin{aligned}
\frac{p(\xi)}{\rho} & =-\frac{q^{2}}{2}-\frac{d \phi}{d t}=\frac{\dot{V} \dot{c}(1+\xi \mu)}{\sqrt{1-\xi^{2}}}-\frac{V^{2}}{2} \cdot \frac{\xi^{2}}{1-\xi^{2}} \\
& +\dot{V} c \sqrt{1-\xi^{2}}
\end{aligned}
$$

where

$$
\xi=\frac{x-\mu c}{c}
$$

$\mu$ is the measure for the asymmetric condition and can be determined as followed

$$
\mu= \begin{cases}f(R)(R-1) /(R+1) & \text { for } R \geq 1 \\ f(1 / R)(R-1) /(R+1) & \text { for } R<1\end{cases}
$$

where $R=\frac{\tan \beta_{2}}{\tan \beta_{1}}$,

and

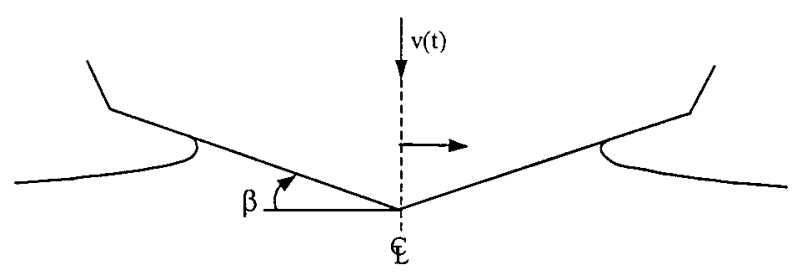

Fig. 1. Water entry of wedge body.
$f(R)=\left\{\begin{array}{cc}0.77975+0.003371 R+0.001876 R^{2} & 1 \leq R<3 \\ 0.76773+0.015024 R-0.000539 R^{2} & 3 \leq R<10 \\ 0.80497+0.007208 R-0.000130 R^{2} & 10 \leq R<20\end{array}\right.$

$\dot{c}$ the time derivativeof the half wetted length, is calculated according to the following expressions

$$
\begin{aligned}
& \frac{c}{c_{o}}=\frac{2 \pi R}{(R+1)^{2}\left(1-\mu^{2}\right) \sqrt{1-\mu^{2}}}, \\
& \text { and } c_{o}=\frac{\delta}{2}\left(\frac{1}{\tan \beta_{1}}+\frac{1}{\tan \beta_{2}}\right)=\frac{V t}{2}\left(\frac{1}{\tan \beta_{1}}+\frac{1}{\tan \beta_{2}}\right)
\end{aligned}
$$

then

$$
\begin{aligned}
\dot{c} & =\frac{2 \pi R}{(R+1)^{2}\left(1-\mu^{2}\right) \sqrt{1-\mu^{2}}} \dot{c}_{o} \\
& =\frac{\pi R V}{(R+1)^{2}\left(1-\mu^{2}\right) \sqrt{1-\mu^{2}}}\left(\frac{1}{\tan \beta_{1}}+\frac{1}{\tan \beta_{2}}\right)
\end{aligned}
$$

All the geometric parameters for the asymmetric slamming calculation are specified in Fig. 2. Although this method is derived by a simple approach, its numerical results are in good agreement with a more sophisticated numerical method recently derived by Scolan [6].

Fig. 3 shows the non-dimensional pressure distributions for four asymmetrical cases. The body is assumedly dropped $1 \mathrm{~m}$ under the still water line. The asymmetric parameters in terms of $\beta_{1}, \beta_{2}$, and $\alpha$ for these four cases are shown in Tab. 1. The heel angle $\alpha$ is defined such that $\beta_{1}=\beta-\alpha$ and $\beta_{2}=\beta+\alpha$. $\beta$ is the dead-rise angle of the edge body in up-right position. The first case is symmetrical with a dead-rise angle of 30 degrees. As shown in Fig. 3, as the asymmetric degree increases, the pressure level becomes higher along the side with the lower dead-rise angle $\beta_{1}$, and the

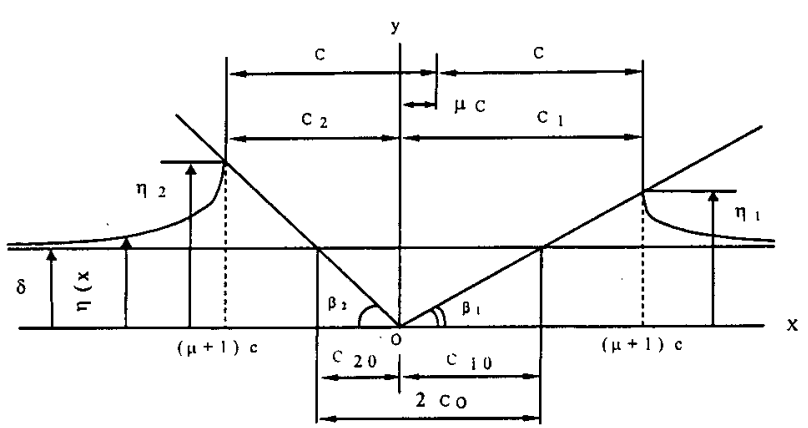

Fig. 2. Water entry of an asymmetric edge body. 
Table 1. Asymmetric condition

Case No. 1 Case No. 2 Case No. 3 Case No. 4

\begin{tabular}{lrrrr}
\hline$\beta_{1}(\mathrm{deg})$ & 30 & 25 & 20 & 15 \\
$\beta_{2}(\mathrm{deg})$ & 30 & 35 & 40 & 45 \\
$\alpha(\mathrm{deg})$ & 0 & 5 & 10 & 15 \\
\hline
\end{tabular}

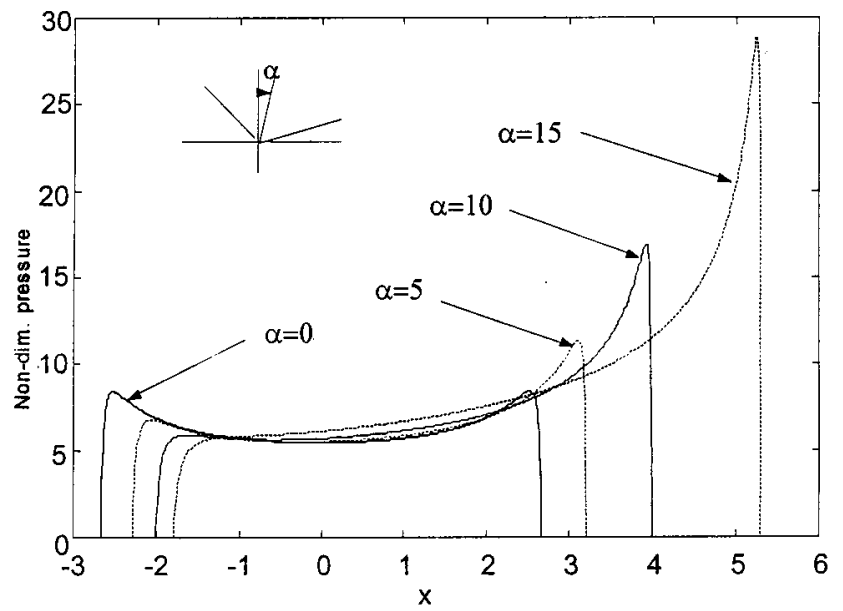

Fig. 3. Non-dimensional pressure distribution due to the water entry of an asymmetric edge body.

pressure front passes faster upward.

\section{Analysis of dynamic response of a plate structure}

We apply the orthogonal plate theory to describe the dynamic behavior of a bottom plate structure supported around the edges by the ship's primary and secondary structures such as girds, web frames and bulkheads. Suppose a rectangular plate, with a dimension of $B$ by $L$ shown in Fig. 4 , is exerted on loads, then the distribution of the plate's deflection is physically governed by the differential equation below

$$
\begin{aligned}
m \frac{\partial^{2} w}{\partial t^{2}}+ & D_{x} \frac{\partial^{4} w}{\partial x^{4}}+2 D_{x y} \frac{\partial^{4} w}{\partial x^{2} \partial y^{2}}+D_{y} \frac{\partial^{4} w}{\partial y^{4}} \\
& =p_{V}(x, y, t)+p_{W}(x, y, t ; w)
\end{aligned}
$$

where $w$ denotes the deflection, $t$ the time, $p_{V}$ the hydrodynamic pressure as the plate has a part of an edged body entry water with a drop velocity $V, p_{W}$ the pressure due to the plate deflection, and $m$ the mass density of the plate.

An orthogonal plate can be used to simulate a stiffened bottom plate structure or a sandwich panel by setting proper coefficients $D_{x}, D_{y}$ and $D_{x y}$ in equation (5), and this will simplify the problem in the present

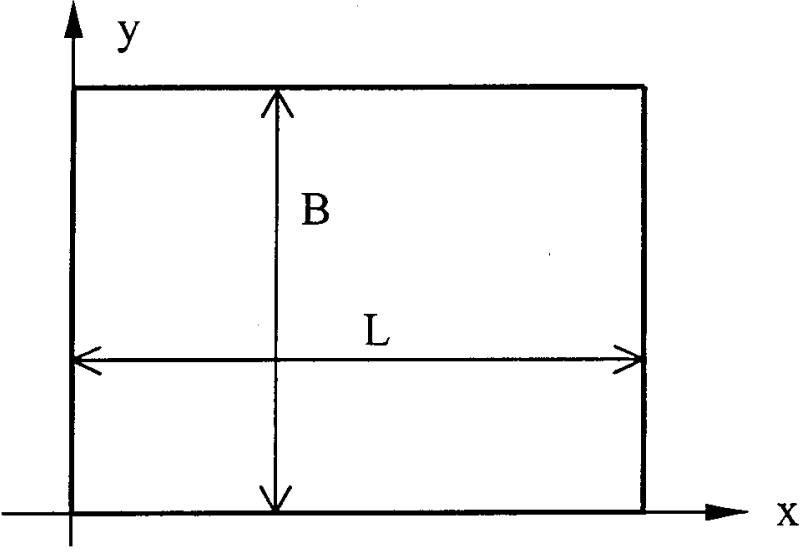

Fig. 4. Plate geometry and the coordinate system.

analysis.

In the numerical analysis, the Vlasov/Galerkin method (see Szilard, [7]) is adopted to solve the differential equation in (5). We assume the deflection of the plate is

$$
w(x, y, t)=\sum_{j} a_{j}(t) \cdot W_{j}(x, y)
$$

The benefit in employing the Vlasov/Galerkin method is that the deflection mode $W_{j}(x, y)$ can be written in the following expression as

$$
W_{j}(x, y)=X_{j}(x) \bullet Y_{j}(y)
$$

where $X_{j}(x)$ and $Y_{j}(y)$ are the functions satisfying the boundary conditions along the four sides of the plate. Hereby, $X_{j}(x)$ and $Y_{j}(y)$ are analogous with the deflection modes of a vibrating beam.

According to the Galerkin method, the following integral equation has to be satisfied for all deflection modes $W_{i}(x, y)$

$$
\begin{gathered}
\int_{0}^{L} \int_{0}^{B} W_{i}(x, y)\left[m \frac{\partial^{2} w}{\partial t^{2}}+D_{x} \frac{\partial^{4} w}{\partial x^{4}}+2 D_{x y} \frac{\partial^{4} w}{\partial x^{2} \partial y^{2}}+D_{y} \frac{\partial^{4} w}{\partial y^{4}}\right] d x d y \\
=\int_{0}^{L} \int_{0}^{B} W_{i}(x, y)\left[p_{v}(x, y, t)+p_{w}(x, y, t ; w)\right] d x d y
\end{gathered}
$$

We define

$$
\begin{aligned}
& m_{i j}=\int_{0}^{L} \int_{0}^{B} W_{i}(x, y) \cdot m \cdot W_{j}(x, y) d x d y \\
& c_{i j}=\int_{0}^{L} \int_{0}^{B} W_{i}(x, y) \cdot\left(D_{x} \frac{\partial^{4}}{\partial x^{4}}+2 D_{x y} \frac{\partial^{4}}{\partial x^{2} \partial y^{2}}+D_{y} \frac{\partial^{4}}{\partial y^{4}}\right)
\end{aligned}
$$




$$
\begin{aligned}
& W_{j}(x, y) d x d y \\
& f_{i}(t)=\int_{0}^{L} \int_{0}^{B} W_{i}(x, y) \cdot p_{V}(x, y, t) \cdot d x d y
\end{aligned}
$$

The time-dependent plate deflection affects the hydrodynamic inertial force and damping force as well. However, an exact solution to $W_{i}(x, y)$ is much more complicated. Therefore the Faltisen's approach in [4] is adopted by assuming a mean deflection over the $y$ direction

$$
\begin{aligned}
\bar{w}(x, t) & =\frac{1}{c(t)} \sum_{i} a_{i}(t) \cdot \int_{0}^{c(t)} W_{i}(x, y) \cdot d y \\
& =\frac{1}{c(t)} \sum_{i} a_{i}(t) \cdot X_{i}(x) \int_{0}^{c(t)} Y_{i}(y) \cdot d y
\end{aligned}
$$

The mean deflection velocity

$$
\begin{aligned}
\dot{\bar{w}}(x, t) & =\frac{1}{c(t)} \sum_{i} \dot{a}_{i}(t) \cdot \int_{0}^{c(t)} W_{i}(x, y) \cdot d y \\
& =\frac{1}{c(t)} \sum_{i} \dot{a}_{i}(t) \cdot X_{i}(x) \int_{0}^{c(t)} Y_{i}(y) \cdot d y
\end{aligned}
$$

The velocity potential due to the deflection velocity

$$
\phi_{w}(x, t)=\dot{\bar{w}}(x, t) \cdot \sqrt{c^{2}(t)-(y-\mu)^{2}}
$$

where $\mu$ is determined by (3).

Then, the hydrodynamic pressure becomes

$$
\begin{aligned}
p_{W}(x, y, t ; w) & =-\rho \frac{d \phi_{w}}{d t}=-\rho \dot{\bar{w}} \frac{c(t) \cdot \dot{c}(t)}{\sqrt{c^{2}(t)-(y-\mu)^{2}}} \\
& -\rho \ddot{\bar{w}} \sqrt{c^{2}(t)-(y-\mu)^{2}}
\end{aligned}
$$

The added masses with respect to the deflection mode can then be calculated by

$$
\begin{aligned}
A_{i j}(t) & =\frac{\rho}{c(x, t)} \int_{0}^{L}\left(\int_{0}^{c(t)} W_{j}(x, y) \cdot d y\right) \cdot X_{i}(x) \cdot d x \\
& \cdot \int_{0}^{c(t)} Y_{i}(y) \sqrt{c^{2}(t)-(y-\mu)^{2}} d y
\end{aligned}
$$

The deflection rate can result in a reduced drop velocity and consequently reduction in the slamming
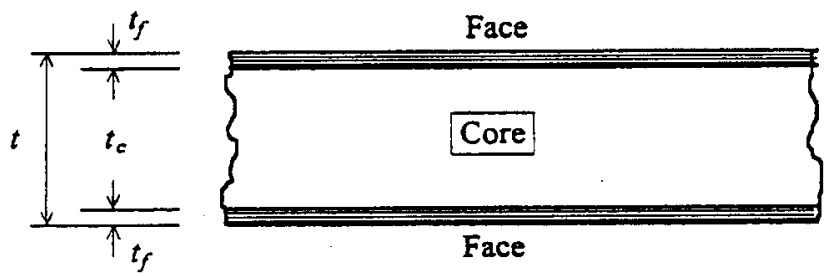

Fig. 5. Sandwich section. effect. As shown later in Fig. 8 and Fig. 10, the maximal lateral deflection is less than $0.04 \mathrm{~m}$ for the investigated plate structure, which will result in a reduction in the drop velocity by less than $2.6 \%$ and the slamming effect by less than $5.3 \%$. Actually, the reduction becomes greater as the structural dynamic response increases.

Since the magnitude of the deflection rate is much less than the drop velocity, its effect on the slamming pressure is then neglected in this study. And the negligence could give the result overestimated in some percent. So, we have the following differential equations

$$
\left[m_{i j}+A_{i j}(t)\right] \cdot \ddot{a}_{j}+c_{i j} \cdot a_{j}=f_{i}(t)
$$

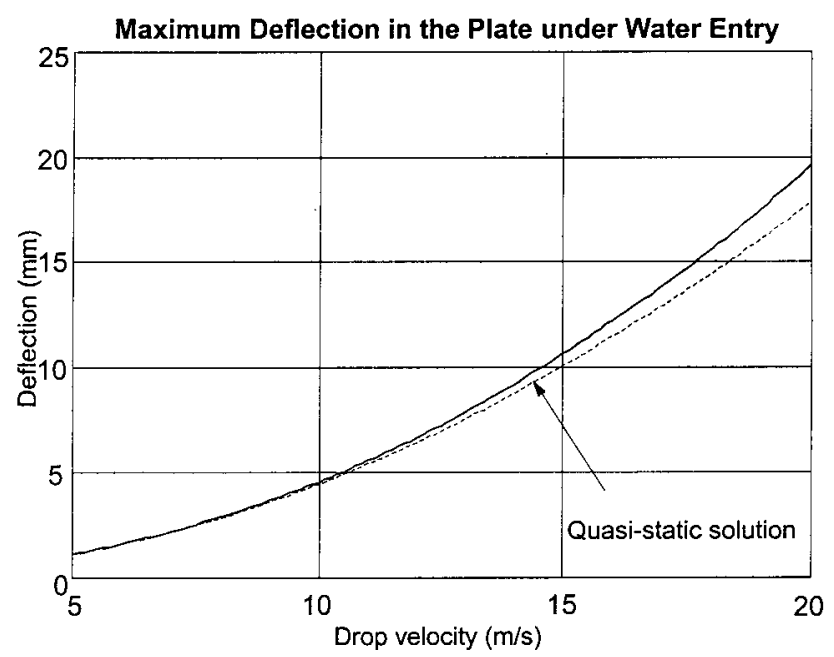

Fig. 6. Maximum deflection in the plate as function of drop velocity. The dead-rise angle is 30 degrees.

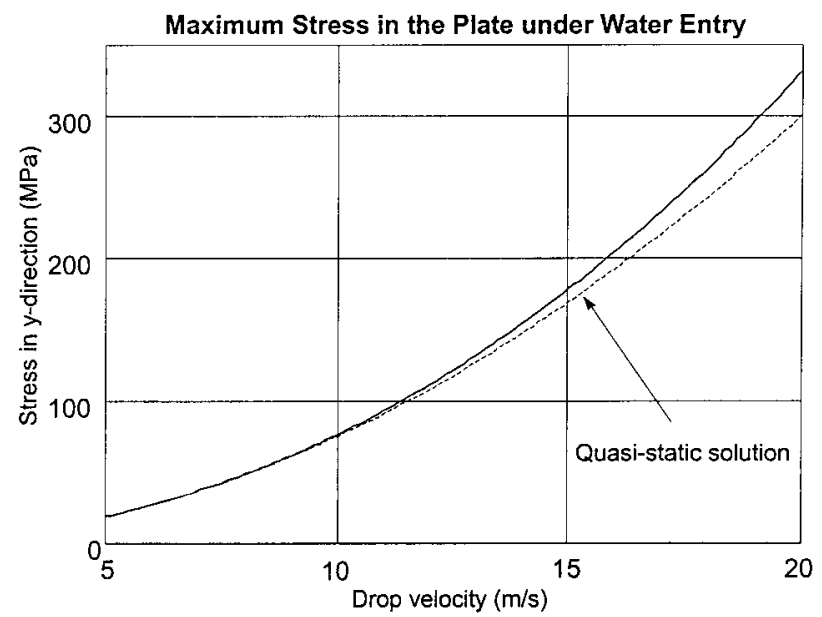

Fig. 7. Maximum stress in y-direction in the plate as function of drop velocity. The dead-rise angle is 30 degrees. 


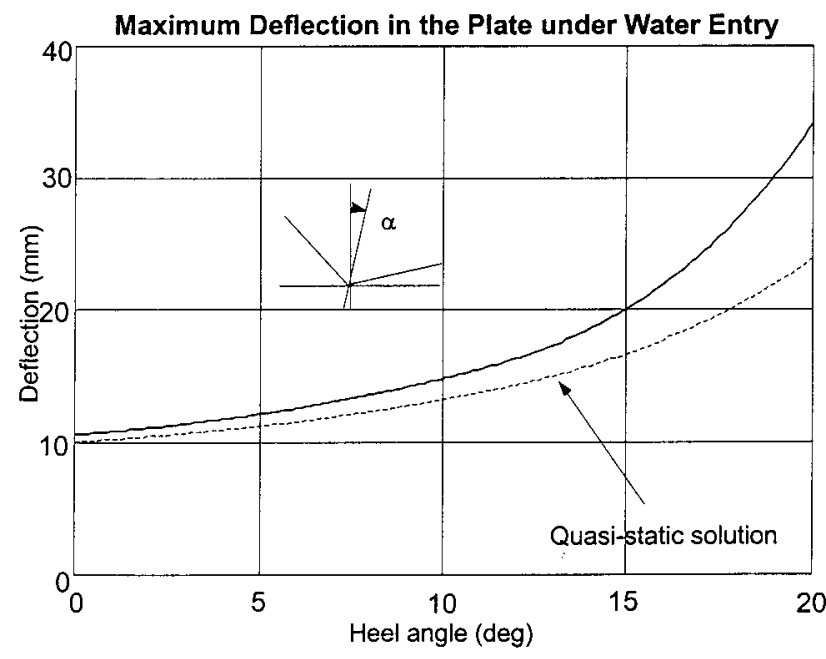

Fig. 8. Maximum deflection in the plate as function of heel angle. The drop velocity is $15 \mathrm{~m} / \mathrm{s}$.

to describe the dynamic behavior of the plate structure. These differential equations are solved numerically by means of the Runge-Kutta method.

For the present study, we choose three deflection modes $W_{1}(x, y), W_{2}(x, y)$ and $W_{3}(x, y)$ for the description of the plate deflected, which are

$$
\begin{aligned}
& W_{1}(x, y)=X_{1}(x) \cdot Y_{1}(y)=D_{1}\left(\frac{\lambda_{1} \cdot x}{L}\right) \cdot D_{1}\left(\frac{\lambda_{1} \cdot y}{b}\right) \\
& W_{2}(x, y)=X_{1}(x) \cdot Y_{2}(y)=D_{1}\left(\frac{\lambda_{1} \cdot x}{L}\right) \cdot D_{2}\left(\frac{\lambda_{2} \cdot y}{b}\right) \\
& W_{3}(x, y)=X_{1}(x) \cdot Y_{3}(y)=D_{1}\left(\frac{\lambda_{1} \cdot x}{L}\right) \cdot D_{3}\left(\frac{\lambda_{3} \cdot y}{b}\right)
\end{aligned}
$$

The deflection mode $D_{i}(x)$ for a beam and the eigenvalues $\lambda_{i}$ of its mode-shapes are determined as the following. Suppose a beam of length has its two ends clamped, the deflection mode $D_{i}(x)$ of the beam is written as

$$
D_{i}(u)=\cosh u-\cos u-\frac{\cosh \lambda_{i}-\cos \lambda_{i}}{\sinh \lambda_{i}-\sin \lambda_{i}}(\sinh u-\sin u)
$$

where $u=\frac{\lambda_{i} \cdot x}{l}$ and $\lambda_{1}=4.73, \lambda_{2}=7.8532$ and $\lambda_{3}=10$. 9956 for the three deflection modes respectively(see [7]).

When the beam is clamped at $x=0$ and hinged at $x=l$, the functions for the deflection modes are the same as in (17), but the eigenvalues become $\lambda_{1}=3.9266, \lambda_{2}$ $=7.0686$ and $\lambda_{3}=10.2102$.

The numerical result has shown that the first three

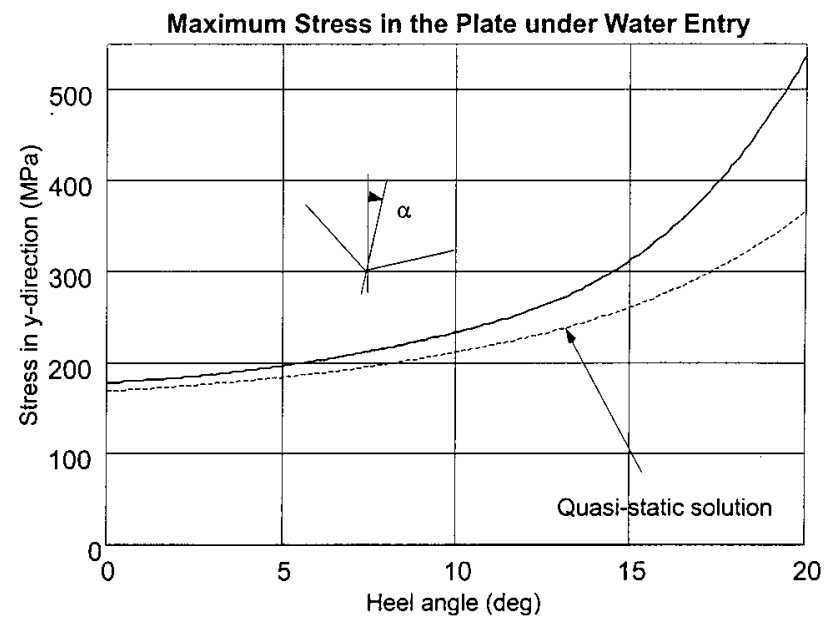

Fig. 9. Maximum deflection in the plate as function of heel angle. The drop velocity is $15 \mathrm{~m} / \mathrm{s}$.

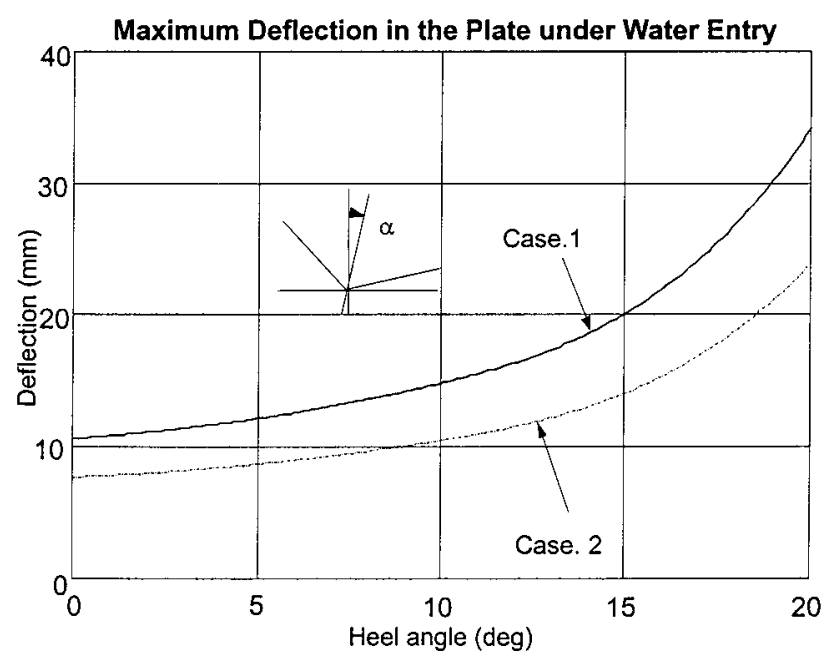

Fig. 10. Maximum deflections in the plate for the two boundary conditions as function of heel angle. The mean dead-rise angle is 30 degrees and the drop velocity $15 \mathrm{~m} / \mathrm{s}$.

deflection modes are sufficiently for representation of the deflection form in the actual study. However, as the drop velocity increases, higher order deflection modes should be added into the mode series.

\section{RESULTS AND DISCUSSIONS}

The dynamic behavior of a square sandwich panel of $1.5 \mathrm{~m}$ by $1.5 \mathrm{~m}$ will be analyzed in the work. The panel is made of FRP structure (Fiber Reinforced Plastic), see Fig. 5, which has the application potential for large size fast ships. The bending stiffness per unit width is 
calculated according to

$$
E I=E_{f} \frac{t_{f}^{3}}{6}+E_{f} t_{f} \frac{\left(t_{f}+t_{c}\right)^{2}}{2}+E_{c} \frac{t_{c}^{3}}{12}
$$

where both subscripts " $\mathrm{f}$ " and "c" refer to the face and the core materials. A typical bottom panel in a ship may have a core thickness $t_{c}=90 \mathrm{~mm}$ and a face thickness $t_{f}$ $=5 \mathrm{~mm}$ (see [3]). Dependent upon the types of fibers used and the lay-up of the faces (laminates), a Young's modulus of about $E_{f}=35 \mathrm{GPa}$ can be obtained. A PVC core with a density of $250 \mathrm{~kg} / \mathrm{m}^{3}$ has a shear modulus of about $G_{c}=100 \mathrm{MPa}$. The bending stiffness is then 8.058 $\times 10^{5} \mathrm{Nm}$. The Young's modulus of the steel material is about $210 \mathrm{GPa}$. The steel plate with the equivalent bending strength will then have a thickness of about 36 $\mathrm{mm}$.

We assume that the laminates give only bending strength to the panel in $x$ - and $y$-directions. The PVC core delivers the torsion strength. becomes

So, the orthogonal property of the sandwich panel

$$
\begin{aligned}
& D_{x}=D_{y}=E I \\
& 2 \cdot D_{x y}=4 \cdot G_{c} \frac{t_{c}^{3}}{12}
\end{aligned}
$$

The stresses in the laminates are calculated by using

$$
\begin{aligned}
& \sigma_{x}=E_{f} \cdot \frac{t_{f}+t_{c}}{2} \cdot \frac{\partial^{2} w}{\partial x^{2}} \\
& \sigma_{y}=E_{f} \cdot \frac{t_{f}+t_{c}}{2} \cdot \frac{\partial^{2} w}{\partial y^{2}}
\end{aligned}
$$

For simplicity, only the stress in $y$-direction will be presented in the following for the demonstration of the asymmetric effect. The stress in $x$-direction has the similar configuration as that in $y$-direction because the sandwich panel is in the square form. For comparison, the quasi-static analysis is also made, i.e. the first term in (5) for the effect of mass inertia is not included when solving the problem.

Fig. 6 shows the maximum deflection in the plate under water entry as the function of the drop velocity. For a large-sized fast ship, the drop velocity designed can be up to $20 \mathrm{~m} / \mathrm{s}$ dependent upon wave conditions considered. This is a symmetric case with a dead-rise angle of 30 degrees. The maximum stress in $y$-direction is shown in Fig. 7. The results of the quasi-static solution are also included in the figures. As seen, both the maximum deflection and the maximum stress are almost proportional to the drop velocity squared. The structural dynamic effect increases as the drop velocity becomes larger, and the present results indicate more

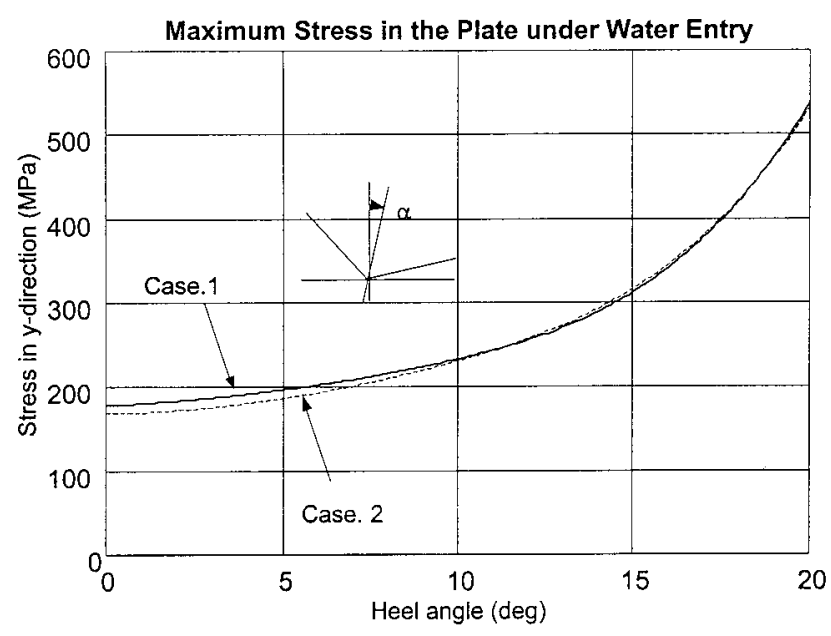

Fig. 11. Maximum stresses in the plate for the two boundary conditions as function of heel angle. The mean dead-rise angle is 30 degrees and the drop velocity $15 \mathrm{~m} / \mathrm{s}$.

deflection and higher stress than the quasi-static approach.

When we study the asymmetric effect, the heel angle $\alpha$ is used as an asymmetric condition. For the plate with a drop velocity of $15 \mathrm{~m} / \mathrm{s}$, Fig. 8 and Fig. 9 show the maximum deflection and the maximum stress respectively as functions of the heel angle. The asymmetric effects on the deflection and stress of the plate are evident. The maximum stress becomes $315 \mathrm{MPa}$ at a heel angle of 15 degrees in comparison with about 180 MPa at a zero heel-angle. That is about a $75 \%$ increase, which is sufficiently significant in the consideration of the ship structural design.

In comparison with the results of the quasi-static solution, the structural dynamic effect increases with the increased heel angle. At a heel angle of 20 degrees, the maximum deflection becomes about 50\% more than that of the quasi-static approach, and the maximum stress in $y$-direction over $40 \%$ the quasi-state approach.

Since the boundary condition of simply supported for the upper-side is an underestimation in restraining degree, the effect of the clamped condition for the upper-side is therefore analyzed. We define the simply supported upper-side as Case. 1 and the clamped as Case. 2. The real problem will then be somewhere between these two extreme cases. Fig. 10 shows the maximum deflections for the two cases of various heel angles. The drop velocity is $15 \mathrm{~m} / \mathrm{s}$. The maximum deflection for different heel angles in Case. 1 is overall greater than Case. 2. The deflection differences between the two cases increase with the increase of the heel angle. However, the difference in the maximum stress in y-direction between Case. 1 and Case. 2 is very 
small, see Fig. 11. Obviously, we can get a good estimation of the stress level in the plate structure for practical problem analysis through the study of these two extreme cases.

\section{CONCLUSION}

In this study, the asymmetric effect is investigated on the deflection and the stress in a plate structure considered as a part of a ship body under water entry. The numerical calculation is carried out for a plate of FRP-sandwich with realistic boundary conditions equivalent to the bottom construction of a fast monohull ship. The numerical results have shown that the effect is significant. Both the deflection and the stress in the plate increase as the asymmetric degree increases.

The explanation to the asymmetric effects is that as an edged body is asymmetrically under water entry, the dead-rise angle at one side becomes lower than the other side. Consequently, the slamming pressure becomes much higher along the side of low dead-rise angle. At the same time, the slamming pressure passes through the side faster. When the pressure front through the plate is sufficiently fast, the deflection and the stress in the plate become more severe due to the structural dynamic effect. Moreover, this dynamic effect also increases with the increasing degree of asymmetric water entry. The present study has shown evidently that the asymmetric impact load and its effect on structure dynamic response are important in the consideration of the structural design of high-speed vessels. It has also demonstrated that the application of the orthogonal plate theory is a practical approach in modeling the structural dynamic response of ship bottom structure. The theory provides faster analysis than the finite element method and therefore is an appropriate alternative in analyzing the problem.

\section{ACKNOWLEDGEMENT}

We highly appreciated the National Science Council of Republic of China for granting the financial support to the work under the Contract No.NSC-892811-E-019-0001.

\section{REFERENCES}

1. Hua, J., "Issues in the Assessment of Design Slamming Pressure on High Speed Monohull Vessels," PRADS'98,
Hague, Netherlands (1988).

2. Rose, A. and Rutersson, O., "Full-Scale Trials on a Small High Speed Naval Craft with Focus on Slamming," OME'98, Liaabon, Portugal (1998).

3. Milchert, T., Hua, J. and Makinen, K., "Design Slamming Pressure on High Speed Mono-hull Vessels" Report KTH/SKP/FR-97/12-SE, Royal Institute of Technology, Sweden (1995).

4. Faltisen, O. M., "Water Entry of a Wedge by the HydroElastic Orthotropic Plate Theory," Journal of Ship Research, Vol. 143, No. 3, pp. 180-193 (1999).

5. Toyama, Y., "Two-dimensional Water Impact of Unsymmetrical Bodies," Journal of the Society of Naval Architects of Japan, Vol. 173 (1993)

6. Scolan, Y. -M., "Etude analytique et numerique de I'impact hydrodynamique sur des carenes dissymetriques," 7e Journees De L'Hydrodynamique, Marseille, Mars (1999).

7. Szilard, R., "Theory and analysis of plates: Classical and numerical methods," Prentice Hall, Inc., Englewood Cliffs, NJ (1974).

\section{非對稱效應所致之水動力衝擊對平 板結構動態分析 華建 波}

瑞典皇家工學院 載具工程學系

$$
\text { 吴俊仁王偉輝 }
$$

\section{國立台灣海洋大學系統工程暨造船學系}

$$
\text { 摘 要 }
$$

基於船舶水下浸水面積於横搖方向之非對稱分 佈事實, 本文乃以正交平板理論並佐以數值計算分析 水動力衝擊之效應對浸水面板結構動態影響。數值結 果發現板應力及變形撓度隨著非對稱現象增加而明顯 增加, 譬如於船舶横傾角20度狀況下, 板最大撓度值 於非對稱效應之考量下較無考慮非對稱效應增加 $50 \%$, 而且於y向之最大應力值亦較無考慮非對稱效 應大 $40 \%$ 。本文結果將可提供船舶設計者, 能考量船 舶於水下浸水部分, 非對稱效應衝擊力對結構強度之 影響。 